\title{
PENGARUH PENGGUNAAN PASIR BALIKPAPAN TERHADAP KEKERASAN DAN FLUIDITAS LOGAM CORAN PADUAN Al-Si
}

\author{
Sabdha Purna Yudha ${ }^{1}$, Halim $^{2}$, Reza Bachmid ${ }^{3}$ \\ ${ }^{1}$ Jurusan Teknik Manufaktur, ${ }^{2,3}$ Jurusan Teknik Alat Berat, Politeknik Batulicin \\ 1 sabdh4@ymail.com
}

\begin{abstract}
Abstrak - Penggunaan pasir sebagai cetakan pada proses pengecoran sangat umum digunakan. Pada penelitian ini digunakan pasir Balikpapan sebagai pasir cetak pengecoran, kemudian dilakukan analisis pengaruhnya terhadap kekerasan dan fluiditas terhadap logam paduan Al-Si. Metode penelitian yang digunakan dalam penelitian ini adalah metode penelitian kuantitatif dengan menggunakan pre-experimental design khususnya model one shot case study. Hasil akhir dari penelitian ini akan didapatkan (1) nilai kekerasan logam hasil pengecoran dengan menggunakan alat uji Micro Vickers Hardness Tester dengan skala Hardness Vickers (HV), (2) pengujian fluiditas dilakukan menggunakan metode Brimingham agar dapat diketahui panjang aliran logam coran (mm) pada hasil akhir pengecoran..
\end{abstract}

Kata Kunci- Pengecoran Logam; Pasir Balikpapan; Kekerasan; Fluiditas

\begin{abstract}
The use of sand as a mold in the casting process is very common. In this study, Balikpapan sand used as casting sand then analyzed its effect on hardness and fluidity of the Al-Si alloy. The research method used in this research is quantitative research methods using pre-experimental design, especially the one-shot case study model. The final results of this study will be obtained (1) the value of metal hardness from casting using the Micro Vickers Hardness Tester with a Hardness Vickers (HV) scale, (2) fluidity testing is carried out using the Birmingham method in order to determine the length of the cast metal flow (mm) on the final result of casting.
\end{abstract}

Keywords: Metal Casting; Balikpapan Sand; Hardness; Liquidity

\section{PENDAHULUAN}

Penggunaan alumunium diberbagai industri otomotif maupun permesinan sangatlah penting, karena sifatnya logam aluminium dapat menahan keausan serta korosi yang baik, tingkat koefisien ekspansi termal rendah, dan juga mempunyai perbandingan antara kekuatan dan berat yang tinggi (Nindhia, 2010). Berbagai macam produk terbuat dari bahan dasar almumunium, dari mulai perabot rumah tangga hingga komponen-komponen mesin dapat dibuat dengan logam ini.

Salah satu proses yang dapat dilakukan untuk membentuk logam adalah dengan pengecoran. Pada proses pengecoran, logam dicairkan didalam tungku peleburan hingga mencapai titik leburnya dan mencair kemudian logam cair tersebut dituangkan kedalam cetakan yang hasil akhirnya dapat berupa berbagai macam produk dari perabotan rumah tangga hingga komponen-komponen mesin dapat dihasilkan dari proses tersebut. Proses -proses dalam pengecoran dengan menggunakan cetakan pasir terdapat tahapan-tahapan, mulai dari menempatkan cetakan dalam tumpukan pasir agar terbentuk pola cetakan yang diinginkan, membuat sistem saluran pada pola, kemudian mengisi rongga cetakan dengan logam cair, membiarkan logam cair yang telah dituang hingga beku, membuka cetakan pasir dan membersihkan hasil coran yang telah terbentuk.
Dalam pemilihan pasir cetak harus memenuhi syarat-syarat diantaranya, memiliki sifat mudah dibentuk, permeabilitas, besar ukuran distribusi pasir yang baik, serta mempunyai ketahanan terhadap temperatur (Surdia, 2015). Pasir balikpapan merupakan salah satu jenis pasir pantai yang memiliki presentase silika ( $\mathrm{SiO} 2)$ yang besar sekitar $94-95 \%$ (hasil uji XRF), sehingga dapat digunakan sebagai pasir dalam proses pengecoran logam. Kekuatan tekan pada cetakan dapat dipengaruhi oleh kadar pengikat yang ditambahkan pada proses pembuatan cetakan dan tidak dipengaruhi oleh ukuran butir pasir (Devianty, 2014).

Tujuan penelitian ini adalah mengetahui pengaruh penggunaan pasir Balikpapan sebagai pasir dalam proses pengecoran logam, serta pengaruh variasi pengikat pada hasil pengecoran logam yang dilihat dari fluiditas hasil akhir produk pengecoran. Maanfaat dari penilitian ini adalah untuk mengetahui bagaimana hasil pengecoran dengan menggunakan pasir Balikpapan sebagai alternatif penggunaan pasir dalam pengecoran logam menggunakan cetakan pasir (sand casting).

\section{METODE}

Dalam penelitian kali ini digunakan penelitian dengan desain penelitian pre-experimental dengan mengambil model one-shot case study, yang mana akan dilakukan sebuah 
perlakuan pada sekelompok sampel dan kemudian akan di observasi hasilnya. Paradigma penelitian yang digunakan adalah paradigma ganda dengan dua variabel independen dan dua variabel dependen seperti tertuang pada gambar berikut;

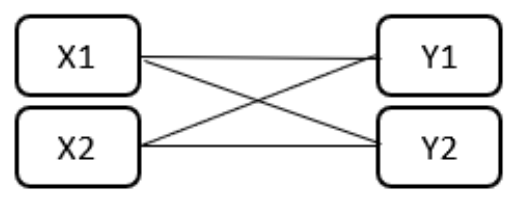

$$
\begin{aligned}
& \text { Keterangan: } \\
& \mathrm{X} 1=\text { Pasir Balikpapan dan Bentonit } 10 \% \\
& \mathrm{X} 2=\text { Pasir Balikpapan dan Bentonit } 15 \% \\
& \mathrm{Y} 1=\text { Sifat mekanik Logam Cor } \\
& \mathrm{Y} 2=\text { Fluiditas Logam Cor }
\end{aligned}
$$

Gambar 1. Desain Penelitian yang Digunakan

Analisa yang dilakukan pada data di penelitian ini dilakukan dengan cara analisis deskriptif. Analisis deskriptif adalah statistik dimana digunakan untuk menganalisa data dengan cara melakukan pendeskripsian atau menggambarkan data yang telah didapat dengan apa adanya tanpa bermaksud membuat kesimpulan yang berlaku untuk umum atau generalisasi (Sugiyono 2013:207). Analisis deskriptif ini digunakan unutk menganalisis kekerasan Micro Vikers dan fluiditas hasil coran pada logam paduan Al-Si.

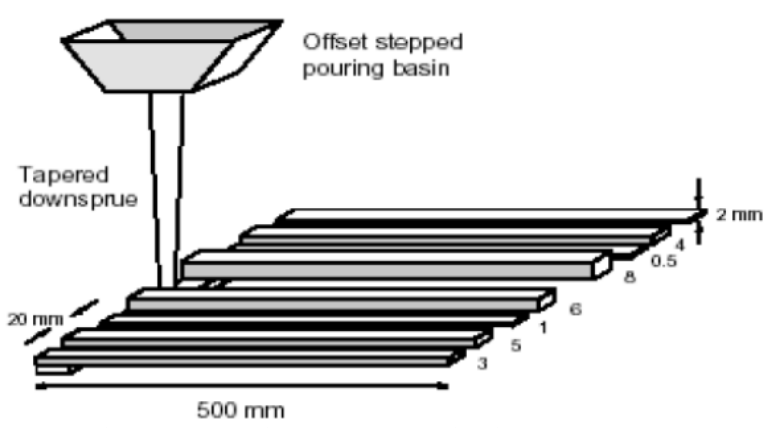

Gambar 2. Metode Pengujian Fluiditas Brimingham

\section{HASIL DAN DISKUSI}

Uji XRF (X-Ray Fluoroscence)

Sebelum melakukan proses pengecoran, terlebih dahulu dilakukan pengujian XRF terhadap semua bahan penelitian antara lain pasir Balikpapan, pasir silika, Pasir Malang, dan Bentonit sebagai pengikat dalam penelitian ini, hasil pengujian tersebut ditunjukan dalam tabel berikut:
Tabel 1. Hasil Uji XRF Sampel

\begin{tabular}{|c|c|c|c|}
\hline \multirow{2}{*}{ No } & \multirow{2}{*}{ Element } & \multicolumn{2}{|c|}{ Consentration Unit (\%) } \\
\cline { 3 - 4 } & & Pasir Balikpapan & Bentonit \\
\hline 1 & $\mathrm{Al}$ & - & 6.8 \\
\hline 2 & $\mathrm{Si}$ & 95.7 & 21.9 \\
\hline 3 & $\mathrm{~K}$ & - & 0.26 \\
\hline 4 & $\mathrm{Ca}$ & 1.4 & 5.05 \\
\hline 5 & $\mathrm{Ti}$ & 0.02 & 2.02 \\
\hline 6 & $\mathrm{~V}$ & 0.10 & 0.14 \\
\hline 7 & $\mathrm{Cr}$ & - & 0.14 \\
\hline 8 & $\mathrm{Mn}$ & 0.37 & 0.44 \\
\hline 9 & $\mathrm{Fe}$ & 1.02 & 60.11 \\
\hline 10 & $\mathrm{Ni}$ & 0.18 & 0.56 \\
\hline 11 & $\mathrm{Cu}$ & - & 0.36 \\
\hline 12 & $\mathrm{Zn}$ & - & 0.15 \\
\hline 13 & $\mathrm{Sr}$ & - & - \\
\hline 14 & $\mathrm{Ba}$ & - & - \\
\hline 15 & $\mathrm{Eu}$ & - & 0.48 \\
\hline 16 & $\mathrm{Re}$ & - & 0.43 \\
\hline 17 & $\mathrm{P}$ & - & - \\
\hline 18 & $\mathrm{~S}$ & - & - \\
\hline 19 & $\mathrm{Mo}$ & - & - \\
\hline 20 & $\mathrm{In}$ & & \\
\hline & & - & 0.3 \\
\hline
\end{tabular}

Dari hasil uji kandungan menggunakan XRF kandungan yang paling dominan dari setiap sampel pasir Balikpapan dan pengikat Bentonit yaitu pasir silika memiliki kandungan $\mathrm{Si}$ pada pasir Balikpapan sebesar $95.7 \%$ sedangkan pada bentonit memiliki kandungan Fe sebesar 60.11\%.

\section{Data Hasil Penelitian Pasir Balikpapan}

Pasir cetak Balikpapan memiliki masing-masing dua variasi pengikat yaitu pasir silika dengan pengikat $10 \%$ serta pengikat $15 \%$ dengan komposisi air sebesar masing-masing 5\%.

\section{Hasil Uji Kekerasan}

Pengujian kekerasan dilakukan untuk mengetahui tingkat kekerasan logam hasil coran. Pada pengujian ini digunakan Micro Vickers Hardness Tester. Menurut Tilley (2004:315) kekerasan suatu logam saling berkaitan erat dengan ikatan kimia logam tersebut, jadi tingkat kekerasan suatu logam hasil pengecoran Al-Si juga dapat dipengaruhi oleh struktur mikro dari logam Al-Si. Skala yang digunakan adalah HV (Hardnees Vickers) dengan penetrasi berbentuk piramid. Pada permukaan spesimen diambil 3 titik secara acak pada tiap-tiap spesimen. Berikut ini adalah data hasil pengujian kekerasan masing-masing spesimen.

\section{Variasi bentonit $10 \%$}

Tabel dibawah adalah tingkat kekerasan hasil coran logam dengan kadar bentonit 10\% dan air 5\%. 
Tabel 2. Hasil Uji Kekerasan Pasir Balikpapan Variasi Bentonit $10 \%$

\begin{tabular}{|c|c|c|c|c|c|}
\hline No. & Sampel & $\begin{array}{c}\text { Titik 1 } \\
\text { (HV) }\end{array}$ & $\begin{array}{c}\text { Titik 2 } \\
(\mathrm{HV})\end{array}$ & $\begin{array}{c}\text { Titik 3 } \\
\text { (HV) }\end{array}$ & $\begin{array}{c}\text { Rata- } \\
\text { rata } \\
(\mathrm{HV})\end{array}$ \\
\hline 1 & Tebal 8 mm & 90.82 & 83.72 & 88.84 & 87.79 \\
\hline 2 & Tebal 5 mm & 86.00 & 87.64 & 84.40 & 86.01 \\
\hline \multicolumn{6}{|c|}{ Rata-rata keseluruhan } \\
\hline
\end{tabular}

Variasi bentonit $15 \%$

Tabel dibawah ini adalah tingkat kekerasan hasil coran dengan komposisi bentonit 15\% dan 5\%

Tabel 3. Hasil Uji Kekerasan Pasir Balikpapan Variasi Bentonit 15\%

\begin{tabular}{|c|c|c|c|c|c|}
\hline No. & Sampel & $\begin{array}{c}\text { Titik 1 } \\
\text { (HV) }\end{array}$ & $\begin{array}{c}\text { Titik 2 } \\
\text { (HV) }\end{array}$ & $\begin{array}{c}\text { Titik 3 } \\
\text { (HV) }\end{array}$ & $\begin{array}{c}\text { Rata- } \\
\text { rata } \\
(\mathrm{HV})\end{array}$ \\
\hline 1 & Tebal 8 mm & 86.69 & 76.85 & 98.57 & 87.37 \\
\hline 2 & Tebal 5 mm & 87.16 & 74.37 & 90.32 & 83.95 \\
\hline \multicolumn{6}{|c|}{ Rata-rata keseluruhan } \\
\hline
\end{tabular}

Dari hasil pengujian didapatkan nilai rata-rata kekerasan tertinggi pada penggunaan pengikat bentonit sebesar $15 \%$ adalah variasi pasir Balikpapan dengan tingkat total rata-rata kekerasan sebesar 85.66 HV. Menurut Widodo (2014) kekerasan pada logam Al-Si berhubungan dengan strukur mikro pada logam Al-Si pada hasil akhir logam coran menggunakan cetakan pasir malang. Pendapat tersebut sesuai dengan Sumanto (1994:13) tingginya nilai kekerasan yang terjadi dikarenakan adanya perbedaan temperatur antara cairan logam coran dengan cetakan yang diguankan, dimana mempengaruhi kecepatan proses, dengan keadaan ini logam dalam keadaan tidak stabil, sehingga laju pengintian (inti menuju ke keadaan yang lain) semakin cepat pula, sehingga struktur butiran yang dihasilkan menjadi tidak stabil. Hal ini dikarenakan butir tidak mempunyai wawktu untuk tumbuh, atau dengan kata lain logam dapat diperkuat dengan cara memperluas batas butir"

\section{Uji Foto Mikro}

Spesimen hasil coran di uji foto mikro untuk melihat struktur mikro pada spesimen coran. Menggunakan perbesaran sebesar 200 kali agar dapat terlihat struktur dari campuran logam yang dihasilkan dari proses pengecoran menggunakan variasi bentonit $10 \%$ dan $15 \%$.

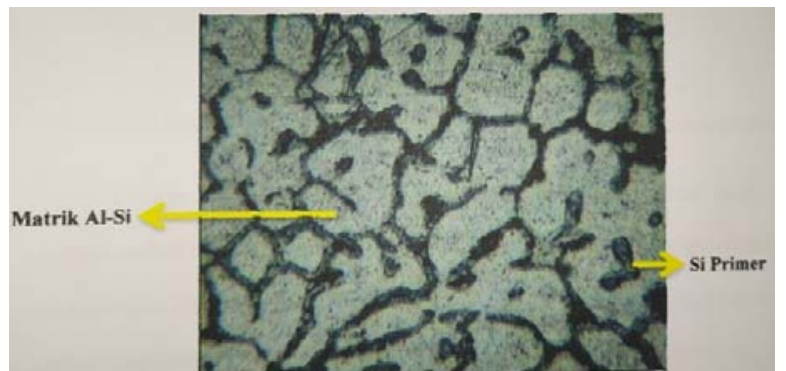

Gambar 2. Foto mikro spesimen dengan variasi pasir balikpapan dan bentonit 10\% dengan perbesaran 200 kali

Gambar diatas memperlihatkan struktur mikro dari logam paduan Al-Si dengan variasi pasir Balikpapan dan bentonit $10 \%$, matriks Al-Si merupakan hasil reaksi antara alumunium dengan silika, sedangkan Si primer merupakan sisa dari silika yang tidak mengalami reaksi dengan logam alumunium. Matriks Al-Si ditunjukan oleh penampilan yang berwarna putih keabu-abuan sedangkan Si primer ditunjukan oeleh enampilan yang berwarna abu-abu kehitaman.

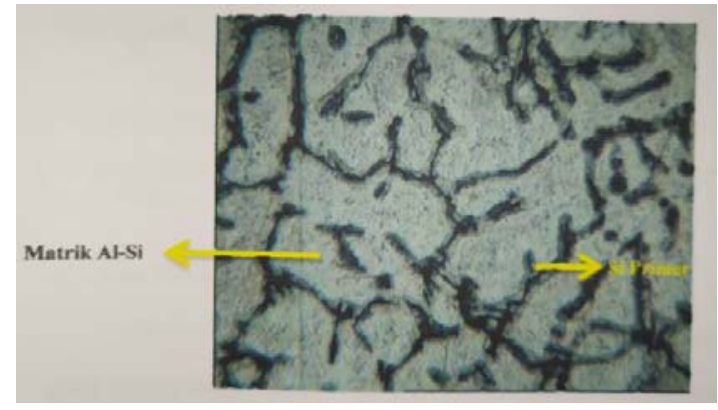

Gambar 3. Foto mikro spesimen dengan variasi pasir balikpapan dan bentonit 15\% dengan perbesaran 200 kali

Gambar diatas memperlihatkan struktur mikro dari logam paduan Al-Si dengan variasi pasir Balikpapan dan bentonit $15 \%$, matriks Al-Si merupakan hasil reaksi antara alumunium dengan silika, sedangkan Si primer merupakan sisa dari silika yang tidak mengalami reaksi dengan logam alumunium. Matriks Al-Si ditunjukan oleh penampilan yang berwarna putih keabu-abuan sedangkan Si primer ditunjukan oeleh enampilan yang berwarna abu-abu kehitaman.

Dari hasil foto mikro didapatkan hasil analisis struktur butiran matriks Al-Si terbesar adalah spesimen dengan variasi pasir Balikpapan dengan pengikat bentonit sebesar $15 \%$. Sedangkan sturktur butiran matriks Al-Si terkecil adalah spesimen dengan variasi pasir Balikpapan dengan pengikat bentonit sebesar 10\%. Menurut Moerta (2009) " sifat mekanik dari suatu logam dapat dilihat dari struktur mikro dari logam tersebut, dimana ukuran butir semakin besar, nilai kekerasannya semakin menurun". Hal yang sama dijelaskan Kurniawan (2014) semakin besar ukuran matriks Al-Si dalam logam paduan Al-Si maka kekerasan permukaan logam Al-Si akan semakin rendah. 


\section{Uji Fluiditas}

Untuk melihat fluditas dari spesimen coran Al-Si, digunakan pola Brimingham dimana pengujian didapat dengan jalan mengukur spesimen coran logam paduan Al-Si secara langsung. Hasil analisis pengukuran dapat dilihat pada tabel berikut

Tabel 4. Hasil uji fluiditas pengecoran pasir Balikpapan dan bentonit $10 \%$

\begin{tabular}{|c|c|c|c|}
\hline \multirow{2}{*}{ No. } & \multicolumn{3}{|c|}{ Ukuran Benda Hasil Coran } \\
\cline { 2 - 4 } & $\begin{array}{c}\text { Panjang } \\
(\mathrm{mm})\end{array}$ & $\begin{array}{c}\text { Lebar } \\
(\mathrm{mm})\end{array}$ & $\begin{array}{c}\text { Tebal } \\
(\mathrm{mm})\end{array}$ \\
\hline 1 & 169 & 20.2 & 7.9 \\
\hline 2 & 50.5 & 20.2 & 3.4 \\
\hline 3 & 92.5 & 20 & 6.5 \\
\hline 4 & 39.5 & 20.4 & 3.8 \\
\hline Total & 351.5 & 81.1 & 19.1 \\
\hline
\end{tabular}

Tabel 5. Hasil uji fluiditas pengecoran pasir Balikpapan dan bentonit $15 \%$

\begin{tabular}{|c|c|c|c|}
\hline \multirow{2}{*}{ No. } & \multicolumn{3}{|c|}{ Ukuran Benda Hasil Coran } \\
\cline { 2 - 4 } & $\begin{array}{c}\text { Panjang } \\
(\mathrm{mm})\end{array}$ & $\begin{array}{c}\text { Lebar } \\
(\mathrm{mm})\end{array}$ & $\begin{array}{c}\text { Tebal } \\
(\mathrm{mm})\end{array}$ \\
\hline 1 & 198 & 20.1 & 8.9 \\
\hline 2 & 69.5 & 20.8 & 3.4 \\
\hline 3 & 139 & 19.2 & 6.5 \\
\hline 4 & 33.5 & 20.2 & 3.8 \\
\hline Total & 440 & 80.3 & 22.6 \\
\hline
\end{tabular}

Dari hasil pengujian fluiditas diatas dapat diketahui bahwa total panjang terbesar dimiliki oleh spesimen dengan variasi pasir Balikpapan dengan pengikat bentonit sebesar $15 \%$ dengan total panjang mencapai $440 \mathrm{~mm}$. sedangkan spesimen yang memiliki lebar total paling mendekati dengan pola adalah spesimen dengan variasi pasir Balikpapan dengan pengikat bentonit $15 \%$ yaitu sebesar $80,3 \mathrm{~mm}$ dibandingkan dengan ukuran total lebar pola yaitu sebesar $80 \mathrm{~mm}$. kemudian spesimen dengan variasi pasir Balikpapan dengan pengikat bentonit $10 \%$ yaitu sebesar 19,1 mm dibandingkan dengan ukuran total tebal pola yaitu sebesar $17 \mathrm{~mm}$.

Aliran logam cair dipengaruhi terutama oleh kekentalan dan oleh kekasaran permukaan cetakan, sedangkan kekentalan tergantung pada temperatur dimana pada temperatur tinggi kekentalan menjasi lebih rendah, dan sebaliknya kekentalan akan menjadi tinggi saat temperatur logam cair menjadi rendah (Surdia 2015:11). Pendapat tersebut sesuai dengan pendapat Kurniawan (2014) +jika pasir cetak memeiliki temperatur yang rendah maka temperatur dari fluida akan lebih cepat turun dan kekentalannya juaga akan lebih meningkat", dan merut Solekah (2012) "Fluiditas suatu logam dapat dipengaruhi oleh ketebalan catakan atau pola"

\section{KESIMPULAN}

Bedasarkan hasil pembahasan diatas maka dapat disimpulkan bahwa penggunaan pasir Balikpapan dengan pengikat bentonit $15 \%$ merupakan yang paling baik karena dilihat dari hasil pengujian fluiditas memiliki nilai total panjang paling besar dibanding dengan spesimen lainnya, sebaliknya jika diinginkan nilai kekerasan yang tinggi dapat dipergunakan pengikat bentonit $10 \%$ pada penggunaan pasir Balikpapan sebagai pasir cetak pada proses pengecoran loagam paduan Al-Si.

\section{REFERENSI}

[1] Arikunto, Suharsimi. 2010. Prosedur Penelitian Suatu Pendekatan Praktik, Jakarta: Rineka Cipta.

[2] Arisuko. 2008. Pasir Cetak. (Online), (http://www.scribd.com/doc/67976652/02-pasir-cetak)

[3] Broto, Opi Wisnu. 2014. Pengaruh Penggunaan Lumpur Lapindo sebagai Bahan Pengikat pada Pasir Cetak Terhadap Kualitas dan Fluiditas Hasil Pengecoran Logam Al-Si, Skripsi tidak diterbitkan. Malang: Universitas Negeri Malang.

[4] Dedy, Sufriansyah. 2013. Pengaruh penggunaan Serbuk Gergaji Sebagai Bahan Pengikat Pada Pasir Cetak Terhadap Kualitas dan Fluiditas Hasil Pengecoran Logam Al-Si, Skripsi tidak diterbitkan. Malang: Universitas Negeri Malang.

[5] Devianty, Sella. 2014. Analisis Kekuatan dan Tekan Cetakan Pasir Akibat Variasi Ukuran Butir dan Kadar Pengikat Pasir Cetak. Jember. Universitas Jember.

[6] Irwanto, Yudi. 2013. Pengaruh Kadar Air dan Bentonir pada Pasir Cetak Malang terhadap Kerataan Permukaan Hasil Coran dan Cacat Coran Logam Alumunium. Skripsi tidak diterbitkan. Malang:Universitas Negeri Malang.

[7] Kalpakjian, Sherope. 1991. Manufacturing Process for Engginering Materials Second Edition. USA:Addison-Wesley Publishing Company Inc.

[8] Kurniawan, Rudi Anggoro. 2014. Pengaruh Penggunaan Variasi Pengikat dengan Pasir Erupsi Gunung Kelud sebagai Pasir Cetak Coran terhadap Kekuatan Pasir, Kualitas, dan Fluiditas hasil Pengecoran Logam Paduan Al-Si. Skripsi tidak diterbitkan. Malang: Universitas Negeri Malang.

[9] Nindhia. Tjokorda. 2010. Studi Struktur Mikro Silikon dalam Paduan Aluminium-Silikon pada Piston dari Berebagai Merek Sepeda Motor. Pamulang. Jurnal Ilmiah Teknik Mesin CakraM Vol. 4 No.1

[10] Sudjana, Hardi. 2008. Teknik Pengecoran Logam (Jilid 1). Jakarta: Direktorat Pembinaan Sekolah Menengah Kejuruan, Direktorat Jendral Manajemen Pendidikan Dasar dan Menengah, Departemen Pendidikan Nasional.

[11] Sugiyono. 2013. Metode Penelitian Pendidikan (Pendekaran Kuantitatif, kualitatif fan R\&D). Bandung: Alfabeta.

[12] Suharto. 1995. Teori Bahan dan Pengaturan Teknik. Jakarta: Rineka Cipta.

[13] Suherman. 2009. Pengaruh Penambahan Sr atau TiB Terhadap Struktur Mikro dan Fluiditas pada paduan Al-6\% Si-0,7\%Fe. Jurnal Dinamis Vol. 2 No. 4, (online), (http://portalgaruda.org/download article.php?article=59121).

[14] Sumanto. 1994. Pengetahuan Bahan Teknik untuk Mesin dan Listrik. Yogyakarta: And I Offset

[15] Surdia, Tata \& Chijiwa, Kenji. 2015. Teknik Pangecoran Logam. Jakarta: Pradnya Paramita.

[16] Solekah, Uswatun. 2012. Analisis Variasi Pasir Cetak Lokal Jawa Timur terhadap Kekuatan Cetakan Pasir Fluiditas dan Kualitas Hasil Coran Logam Al-Si dengan Metode Grafitasi Casting. Skripsi tidak diteterbitkan. Malang: Universitas Negeri Malang.

[17] Tilley, Richar J.D. 2004. Understanding Solid (the Science of Materials). West: John Wiley dan Sons Ltd. 
[18] Widodo, Toni Prasetiyo, 2014. Pengaruh Kadar Semen Portland dalam Pasir Cetak terhadap Kekuatan Cetakan Pasir, Permeabilitas, Fluiditas, Kekerasan Logam dan Kualitas Coran Logam Al-Si dengan Metode Gravity Casting. Skripsi tidak diterbitkan. Malang: Universitas Negeri Malang 